\title{
Timed Up and Go Test Performance as an Indicator of Fall History in Institutionalized Elderly
}

\author{
A Pilot Study
}

\author{
José C. Millán-Calenti, MD, PhD; Laura Núñez-Naveira, PhD; Laura Lorenzo-López, PhD; \\ José L. Rodríguez-Villamil, MD, PhD; Carmen L. Muñoz-Mendoza, PhD; \\ [AQ00] M. José Cabañero-Martínez, PhD; Julio Cabrero-García, PhD; Ana Maseda, PhD
}

Background: Ageing is associated with sensory and physical declines and falling risk.

Objective: To determine the association between 3 performance-based mobility tests and fall history. Methods: Fifty participants' mobility was assessed by Timed Up and Go (TUG) and 4- and 6-m walking tests (WT). Results: The TUG performance correlated with 4- and 6-m WT performance, and performance on 4-m WT positively correlated with 6-m WT. Only TUG performance showed a strong relationship to fall history.

Conclusions: Performance tests could indicate the presence of fall history in the institutionalized older adults; the TUG being the most suitable compared with other common WT. Key words: fall risk, institutionalization, older adults, walking test

I ncreases in life expectancy have triggered demographic changes in developed societies where the world's population aged 65 years or older is expected to grow to nearly 1.5 billion in $2050 .{ }^{1}$ The aging of the population implies an increasingly high prevalence of chronic and degenerative diseases, which are a major cause of death in

Author Affiliations: Universidade da Coruña, Gerontology Research Group, Instituto de Investigación Biomédica de A Coruña (INIBIC), Complexo Hospitalario Universitario de A Coruña (CHUAC), Sergas, A Coruña, Spain (Drs Millán-Calenti, Lorenzo-López, Rodríguez-Villamil, and Maseda); Research, Development and Innovation Department, Gerontological Complex La Milagrosa, Provincial Association of Pensioners and Retired People (UDP) from A Coruña, A Coruña, Spain (Dr Núñez-Naveira); Department of Nursing, University of Bío-Bío, Concepción, Chile (Dr Muñoz-Mendoza); and Department of Nursing, University of Alicante, San Vicente del Raspeig, Alicante, Spain (Drs Cabañero-Martínez and Cabrero-

[AQ01] García).

The authors sincerely thank the Gerontological Complex La Milagrosa and its residents for the facilities provided to carry out this study.

The authors have disclosed that they have no significant relationships with, or financial interest in, any commercial companies pertaining to this

[AQ02] article.

Correspondence: Ana Maseda, PhD, Gerontology Research Group, Department of Medicine, Faculty of Health Sciences, Universidade da Coruña, Campus de Oza, E-15071, A Coruña, Spain (amaseda@udc.es). the older adults, along with a decrease in their mobility and physical functioning. ${ }^{2}$

Poor physical performance implies an increased risk of falling that may result in undesirable physical consequences, including bone fractures, bruises, and injuries. ${ }^{3}$ Fallers have poorer balance, functional mobility, and lower quality of life than nonfallers. ${ }^{4,5}$ In addition, fall risk factors include some common age-related deficits such as gait dysfunction or muscle weakness, visual and hearing deficits, and cognitive impairment. ${ }^{6}$ The prevalence of hearing loss in elderly European people is very high and increases with advancing age. ${ }^{7}$ Hearing loss has also been associated with self-reported falling, ${ }^{8}$ higher total medical expenditures, ${ }^{9}$ and institutionalization. ${ }^{10}$ Given the impact that falls may have on older adults' health, and because falls are a potentially modifiable risk factor, further research in this area is crucial.

In addition to physical consequences, falls might cause a decline in functional status or social activities, generating fear of falling, and a decrease in the functional independence of the older adults. ${ }^{3}$ Consequently, they may need long-term care in the form of home assistance, community care and assisted living, residential care, or long-stay hospitals. ${ }^{3}$ Nevertheless, rates of falling in people living in long-term care institutions are double those of community-dwelling people, ${ }^{6}$ constituting an extra burden on the health care system.

Walking is a common physical activity among the older adults and it is associated with functional fitness. ${ }^{11}$ Thus, walking assessment may be used to explore the mobility function of community-dwelling older adults, ${ }^{12}$ differentiating fallers from nonfallers ${ }^{12,13}$ and acting as a valid indicator of cognitive functioning and other adverse outcomes. ${ }^{14}$ But many of the walking tests (WTs) are complex, timeconsuming, and hard to perform by impaired older adults, highlighting the need to use less complex assessments.

Performance of the Timed Up and Go (TUG) test ${ }^{15}$ is a reliable predictor of clinical, functional, and social variables, and of fall risk. In addition, TUG values have been shown 
to be the strongest predictors for 6-m WT values. ${ }^{16,17}$ As for the WT, the 4- and 6-m WT were considered the main instruments in research on functional ability in the older adults after a standardized assessment in which the 4-m WT achieved the best rating. ${ }^{18}$ Walking speed has been shown to be a good predictor of fall risk, ${ }^{19,20}$ and $4 \mathrm{~m}$ has been considered an adequate distance to evaluate walking speed $^{21}$ and physical performance in elderly with cognitive impairment. ${ }^{22}$ Slower 6-m walk speed contributes to risk of falling, ${ }^{19}$ being this test validated as one of the best mobility tests to predict falls. ${ }^{23}$ Another walking speed test, the $10-\mathrm{m}$ WT, was also associated with the risk of falling. ${ }^{24}$ The 4-m WT does not produce a learning effect ${ }^{25}$ and has sex-specific correlates. ${ }^{26}$ In addition, both tests have demonstrated validity for assessing the walking speed of older adults with cognitive impairment. ${ }^{22}$

To our knowledge, although TUG test and 4-m and 6-m WT have been previously investigated to predict falls, research has not considered its joint analysis as a function of the presence versus absence of previous fall history and older adults versus old older adults (85 years of age or older). Based on the aforementioned text, this research aimed to determine the applicability of 3 common performance-based mobility tests to a specific population of day care versus institutionalized older adults, with 2 main aim goals (1) to determine the correlations in the performance of the 3 tests (considering also differences in the oldest individuals, 85 years of age or older) and (2) to determine their association with fall history. In addition, we aimed to determine the relationship between fall history and hearing impairment. Consequently, the most suitable test could be proposed as a quick screening tool for the older adult population for early detection of mobility impairment and its negative consequences, thus putting a major focus on health prevention rather than disease management.

\section{MATERIALS AND METHODS}

\section{Study design}

Before beginning the data collection and assessments, the protocol of this study was approved by the ethics committee at the University of A Coruña and was in conformity with the principles embodied in the Declaration of Helsinki. A cross-sectional observational study was carried out with 50 people 65 years of age and older selected from a population of 119 people belonging to the Gerontological Complex La Milagrosa from A Coruña, Spain, which includes a day care center and a nursing home. Core services provided by the day care center include small group training on memory, activities of daily living, reality orientation, and cognitive stimulation. Nursing home services additionally offer a 24-hour room, supervision, and nursing care (personal care, medication management and administration, palliative care, rehabilitation, activities, and transportation).
At study commencement, the participants' clinical records were first reviewed to screen for the exclusion criteria. Participants with cardiac or respiratory pathologies, which could be aggravated by exercise, were excluded from the study, as were those with severe visual problems that impeded their evaluation, people who were unable to walk at least $10 \mathrm{~m}$ without assistance, and people incapable of understanding simple verbal commands to walk. After applying the exclusion criteria, 55 users were eligible. Five users with reported missing data (hospitalization $[\mathrm{n}=2]$, immobility $[\mathrm{n}=1]$, refusal to take part $[\mathrm{n}=1]$, and leaving the center $[n=1]$ ) were excluded.

Once selected, all the participants gave written informed consent (inclusion criteria), either autonomously or through their proxies as legally authorized representatives of those with dementia. Reporting of this study follows the STrengthening the Reporting of OBservational Studies in Epidemiology (STROBE) guidelines for cross-sectional studies (www.strobe-statement.org).

\section{Data collection}

\section{Demographic and clinical data}

The internal clinical database of the Gerontological Complex, with information belonging to the participants, was reviewed for the collection of covariates. The following demographic variables were recorded: age, gender, marital status, educational level, and the type of assistance (day care center vs nursing home). Risk factors such as visual and hearing impairment were also reported by the medical staff on the basis of the clinical data or after ad hoc examination. A Snellen eye chart located at a distance of $2.8 \mathrm{~m}$ from participant's eyes was used for screening for visual acuity impairment. Decreased visual acuity was defined as best corrected vision worse than 20/50. ${ }^{27}$ To determine hearing loss, the whispered voice test was used. ${ }^{28}$ The participants were considered to have normal hearing if they repeat back at least 3 out of a possible total of 6 letters/ numbers correctly. Hearing impairment was defined as the inability to repeat back the letter/number combination whispered at a distance of $0.6 \mathrm{~m}$ behind the participant's field of vision.

The Spanish validation of the Mini-Mental State Examination ${ }^{29,30}$ was used as a measure of cognitive impairment. Mini-Mental State Examination scores, ranging from 0 to 30 , were adjusted for age and level of education, and participants were considered as cognitively impaired if they scored 24 or less.

The main outcome of the study was the number of falls during the preceding 6 months extracted from the medical history. According to their fall history, participants were divided into 2 groups: fallers, those who had undergone 1 or more falls in the past 6 months $(n=9)$; and nonfallers, those who had not fallen in the previous 
6 months $(n=41)$. From a clinical point of view, no distinctions were made between single and multiple falls due to a falling event being considered enough to negatively affect the health status of the participant.

\section{Performance tests}

Two trained research nurses with clinical geriatric experience collected the data. Training included instructions and supervised practice in performance-based mobility testing. Both professionals administered the 3 WTs. The TUG test, ${ }^{15}$ the 4-m WT, and the 6-m W $\mathrm{WT}^{16}$ have proven to be wellvalidated and reasonably brief tools in research and clinical practice. The TUG test was randomly applied before $(\mathrm{n}=24)$ or after $(\mathrm{n}=25)$ the 2 WTs. One participant could not perform the TUG test because of severe physical disability. The 4- and 6-m WTs were administered alternatively with 10 minutes of rest between each performance measure.

The TUG test ${ }^{31}$ has been commonly used to measure the mobility skills of older adults. Each participant stood up from a seated position without using his or her hands, walked for $3 \mathrm{~m}$, then turned and sat again without using his or her hands. Participants were given the following instruction: "I want you to stand up, walk the line on the floor at your normal pace, turn around and walk back to the chair and sit down." A walking aid was used if needed and the amount of required time to walk (seconds) was recorded. Timing began on the word "start" and ended when the participant returned to the seated position.

Performance on the 4- and 6-m WT ${ }^{16}$ has been commonly associated with adverse events and cognition in the elderly. ${ }^{32}$ To perform the test, the protocol instructions were simplified. ${ }^{22}$ Participants walked the target distance at a normal pace, using a walking aid if necessary. They were told to stand with their feet touching the starting line and were then given the following instruction: "I want you to walk until you cross that line, at your normal speed, as if you were walking down the corridor," and they began walking when they received the simple order: "Start walking." Timing began the moment the participant initiated a step and ended when the leading foot crossed the finish line.

For this study, walking speed was not calculated; hence, only the time spent in seconds to perform the test was recorded.

\section{Statistical analysis}

Quantitative variables were expressed as the mean (SD). Qualitative variables were expressed as absolute values and percentages. The goodness of fit to a normal distribution of the continuous variables was analyzed using the Kolmogorov-Smirnov test. Because of the small sample size, between-group comparisons (nonfaller vs fallers; aged $<85$ years vs aged $\geq 85$ years) were made using the MannWhitney $U$ test. Chi-square test was used for categorical variables. The variable of age was dichotomized, dividing the participants using the median age ( 85 years) as the cutoff point (the median generated the oldest-old group; those older than 85 years vary widely in terms of demography and social and health characteristics). Associations among the 3 WTs were tested using Pearson correlation coefficient. A forward stepwise multiple logistic regression analysis was made to examine cross-sectional associations between fall history and performance on mobility tests to ascertain the effect of every test outcome regarding the likelihood of participants having a fall. In addition, type of assistance and hearing impairment were included as independent variables, because of the differences between fallers and nonfallers in these 2 areas shown by bivariate analysis. Falling was considered as the outcome variable while the explanatory variables were performance on the 4-m W'T, 6-m W'T, or the TUG.

Sensitivity was calculated as the percentage of true positives identified by the regression model. Odds ratios along with the 95\% confidence intervals (CI) were calculated. A significance value of less than .05 was defined. Statistical analysis was performed using the software package IBM SPSS Statistics v.23.0 (IBM Corp, Armonk, New York).

\section{RESULTS}

\section{Participants' descriptive statistics}

Only 9 participants (18\%) reported at least 1 fall in the past 6 months. Table 1 shows the general characteristics of the study population, according to assignment to faller and nonfaller groups. For the sociodemographic aspects, no differences were found regarding gender, civil status, or level of education. However, we found statistically significant differences $(P=.02)$ according to age and type of assistance (day care center vs nursing home, $P=.04$ ). Fallers $(88.2 \pm 4.0$ years $)$ were significantly $(P=.01)$ older than nonfallers $(82.8 \pm 6.0$ years $)$. The mean age in the oldest age group was significantly higher $(88.2 \pm 2.8$ years vs $78.5 \pm 4.4$ years, $P<.001)$. However, there were no significant differences between the 2 age groups in any of the studied variables.

Regarding clinical characteristics, no statistically significant differences were found between fallers and nonfallers when analyzing visual impairment or cognitive impairment. Nevertheless, we found that fallers had a significantly greater prevalence of hearing impairment $(P=.03)$.

\section{Performance assessment}

Regarding the TUG and the 4-m and 6-m tests, the mean time in seconds was $19.1 \pm 8.4,8.1 \pm 4.0$, and $11.3 \pm 5.0$, respectively. No significant differences were found depending on the time of TUG test application (before or after the other 2 WT). In addition, no significant differences were observed in performance according to gender, civil status, level of education, or type of assistance. Nevertheless, as 


\begin{tabular}{|c|c|c|c|c|c|c|c|c|c|c|}
\hline Characteristics & \begin{tabular}{|c|}
$\begin{array}{c}\text { Nonfaller } \\
(\mathrm{n}=41) \\
\mathrm{n}(\%)\end{array}$ \\
\end{tabular} & $\begin{array}{c}\text { Faller } \\
(\mathrm{n}=9) \\
\mathrm{n}(\%)\end{array}$ & $\chi^{2}$ & $d f$ & $P$ & $\begin{array}{c}\text { Age }<85 \text { y } \\
(n=23) \\
\end{array}$ & $\begin{array}{c}\text { Age } \geq 85 y \\
(n=27)\end{array}$ & $x^{2}$ & $d f$ & $P$ \\
\hline Age, $y$ & & & 5.378 & 1 & $.02^{\mathrm{a}}$ & & & & & \\
\hline$<85$ & $22(53.7)$ & $1(11.1)$ & & & & & & & & \\
\hline$\geq 85$ & $19(46.3)$ & $8(89.8)$ & & & & & & & & \\
\hline Gender & & & 0.034 & 1 & .85 & & & 0.986 & 1 & .32 \\
\hline Male & $8(19.5)$ & 2 (22.2) & & & & 6 (26.1) & $4(14.8)$ & & & \\
\hline Female & $33(80.5)$ & $7(77.8)$ & & & & $17(73.9)$ & $23(85.2)$ & & & \\
\hline Civil status & & & 0.199 & 2 & .91 & & & 1.715 & 2 & .42 \\
\hline Single & $4(9.7)$ & $1(11.1)$ & & & & $3(13.0)$ & $2(7.4)$ & & & \\
\hline Married & $7(17.1)$ & $1(11.1)$ & & & & $5(21.7)$ & $3(11.1)$ & & & \\
\hline Widowed & 30 (73.2) & $7(77.8)$ & & & & $15(65.3)$ & $22(81.5)$ & & & \\
\hline Level of education & & & 2.094 & 4 & .72 & & & 6.616 & 4 & .16 \\
\hline Unable to read or write & $1(2.4)$ & $0(0.0)$ & & & & $0(0.0)$ & $1(3.7)$ & & & \\
\hline Incomplete primary school & $15(36.6)$ & $4(44.4)$ & & & & $8(34.8)$ & $11(40.7)$ & & & \\
\hline Completed primary school & $18(43.9)$ & $5(55.6)$ & & & & $9(39.1)$ & $14(51.9)$ & & & \\
\hline High school or university & $7(17.1)$ & $0(0.0)$ & & & & $6(26.1)$ & $1(3.7)$ & & & \\
\hline Type of assistance & & & 4.134 & 1 & $.04^{\mathrm{a}}$ & & & 0.828 & 1 & .36 \\
\hline Day care center & $32(78.0)$ & $4(44.4)$ & & & & $18(78.3)$ & $18(66.7)$ & & & \\
\hline Nursing home & $9(22.0)$ & $5(55.6)$ & & & & $5(21.7)$ & $9(33.3)$ & & & \\
\hline \begin{tabular}{|l|} 
Presence of visual impairment \\
\end{tabular} & $30(73.2 \%)$ & $6(66.7 \%)$ & 0.155 & 1 & .69 & $18(78.3)$ & $18(66.7)$ & 0.828 & 1 & .36 \\
\hline Presence of hearing loss & $8(19.5)$ & $5(55.6)$ & 4.983 & 1 & $.03^{\mathrm{a}}$ & $4(17.4)$ & $9(33.3)$ & 1.641 & 1 & .20 \\
\hline Presence of cognitive impairment & $36(87.8 \%)$ & $9(100 \%)$ & 1.220 & 1 & .27 & $20(87.0)$ & 25 (92.6) & 0.438 & 1 & .51 \\
\hline \multicolumn{11}{|l|}{ a Significant ( $P$ value $)<.05$. } \\
\hline
\end{tabular}

expected, significant differences in the 4-m and 6-m WT performances were found when comparing participants who are younger than 85 years and those who are 85 years of age or older (Table 2). Time in seconds was greater for people older than 85 years than for their younger counterparts on the $4-\mathrm{m}(P=.03)$ and $6-\mathrm{m}$ W'T assessment $(P=$ .02). This tendency was also observed on the TUG tests, but the differences were not statistically significant.

The TUG performance significantly correlated with 4and 6-m WT performance $(r=0.728 ; P<.001 ; 95 \% \mathrm{CI}$ : $0.669-0.882$ for $4-\mathrm{m} \mathrm{WT}$; and $r=0.764 ; P<.001$; 95\% CI: $0.652-0.911$ for $6-\mathrm{m} \mathrm{WT}$ ), and there was a high positive correlation between 4- and 6-m WT performance $(r=$ $0.915, P<.001 ; 95 \%$ CI: 0.873-0.969).

We found that fall history was associated to WT performance (Table 3). The time that the participants took to perform every WT was significantly higher for people who had undergone at least 1 fall in the previous 6 months than for those who had not fallen.
Results of the regression model were statistically significant, $\chi_{1}^{2}=5.009, P=.03$, and identified the TUG test as being the only variable significantly related to falls $(P=.04)$, with a $\beta$ value of .097 , and an odds ratio value of 1.102 (95\% CI: $1.006-1.207$, those participants taking more time to perform the TUG test were 1.102 times more likely to have suffered a fall). A model with a -2 likelihood ratio of 33.198, Cox and Snell $R^{2}$ of 0.110 , explained $18.7 \%$ (Nagelkerke $R^{2}$ ) of the variance in falls and a correct classification of the cases reporting falls of $86.0 \%$.

\section{DISCUSSION}

This study analyzed not only the correlation of the results obtained with 3 different tests to evaluate the mobility of the day care versus institutionalized older adult population but also their association with fall history. The correlations between the 3 testing outcomes were confirmed and the performance on the TUG was the best predictor of the presence of a previous fall history.

Copyright $\odot 2017$ Wolters Kluwer Health, Inc. Unauthorized reproduction of this article is prohibited. 


\begin{tabular}{|c|c|c|c|}
\hline Walking Tests & $\begin{array}{c}\text { Age }<85 \text { y }(n=23) \\
\text { Mean } \pm \text { SD }\end{array}$ & $\begin{array}{c}\text { Age } \geq 85 \text { y }(n=27) \\
\text { Mean } \pm \text { SD }\end{array}$ & $P$ \\
\hline 4-m WT & $6.8 \pm 2.3$ & $9.1 \pm 4.8$ & $.03^{\mathrm{a}}$ \\
\hline 6-m WT & $9.7 \pm 4.0$ & $12.8 \pm 5.4$ & $.02^{\mathrm{a}}$ \\
\hline TUG & $17.2 \pm 6.5$ & $2.9 \pm 9.5$ & .10 \\
\hline
\end{tabular}

Walking speed is commonly used in health care to measure lower extremity function or physical condition with large variance in the methodology applied. Given that the decline in walking speed is associated with poor health outcomes in the older adults, ${ }^{33}$ the measurement of this parameter has been commonly used for the early detection of factors such as the risk of hospitalization, ${ }^{34}$ declines in instrumental activities of daily living performance,,$^{35}$ falls ${ }^{36}$ nursing home placement, and mortality. ${ }^{28}$ Walking tests differ according to the distance or time utilized. Those tests with longer distances are more focused on assessing endurance or submaximal exercise capacity, such as the 6-minutes WT. ${ }^{37}$ Other tests measure gait speed over a relatively short distance, without including endurance as a factor ${ }^{38}$ thus concentrating more on functional performance measurement. They are preferably used for the older adult population since they require less effort from the participant. In any case, the correlation between some of the long- and short-distance tests and the test-retest and interrater reliabilities have already been demonstrated. ${ }^{39}$

The TUG test ${ }^{15}$ is more commonly used to measure mobility skills while 4- and 6-m WTs are mainly used to assess adverse events and cognition in the older adults. ${ }^{18}$ Their interrater and test-retest reliabilities have been already tested with a population with mild cognitive impairment. ${ }^{22}$ Nevertheless, no data were found in the literature about the correlations between these 3 tests or the different variables that may affect their performance.
The TUG test along with the 4- and 6-m WT was applied to a population composed of day care and institutionalized participants (nursing home). The mean time scores on the 3 mobility tests were consistent with those previously published. ${ }^{22,40}$ No differences were found in test performance according to gender, civil status, level of education, or type of assistance. Therefore, in accordance with the previous literature, this study shows that these 3 W'Ts are easy to perform by institutionalized older adults. ${ }^{22,41}$

In addition, there were substantial and positive correlations between the 3 tests. The TUG results correlate more strongly with the 6-m WT results than with the 4-m WT results, perhaps due to the similar distance in both tests, although the time spent for TUG performance was a little bit higher than that for 6-m W'T performance. A possible [AQ03] explanation might be that reaction time increases according to age and the tasks demands, ${ }^{42}$ and the demands in the TUG test are higher, involving more complex instructions such as sitting, standing up, walking, turning around, walking back, and sitting again. The association between the 4- and 6-m WTs was stronger, perhaps because their similarity in performance and distance, reinforcing previous data indicating that these are valid and reliable instruments. ${ }^{22}$

However, and in accordance with other studies, we found that test performance was affected by a previous fall event. ${ }^{13}$ We noted that those participants who had experienced at least 1 fall during the previous 6 months took

\begin{tabular}{|c|c|c|c|}
\hline Walking Tests & $\begin{array}{c}\text { Nonfaller }(n=41) \\
\text { Mean } \pm \text { SD }\end{array}$ & $\begin{array}{c}\text { Faller }(n=9) \\
\text { Mean } \pm \text { SD }\end{array}$ & $P$ \\
\hline 4-m WT & $7.6 \pm 4.0$ & $10.7 \pm 3.1$ & $.004^{a}$ \\
\hline 6-m WT & $10.6 \pm 4.9$ & $14.4 \pm 4.3$ & $.004^{a}$ \\
\hline TUG & $17.7 \pm 6.7$ & $26.5 \pm 12.1$ & $.02^{b}$ \\
\hline \multicolumn{4}{|c|}{$\begin{array}{l}\text { Abbreviations: TUG, Timed UP and Go; WT, Walking test. } \\
{ }^{\circ} \text { Significant }(P \text { value })<.01 \text {, Mann-Whitney } U \text { test. } \\
{ }^{b} \text { Significant }(P \text { value })<.05 \text {, Mann-Whitney } U \text { test. }\end{array}$} \\
\hline
\end{tabular}

Copyright $\odot 2017$ Wolters Kluwer Health, Inc. Unauthorized reproduction of this article is prohibited. 
more time to perform the assessment tests, suggesting that they might act as indicators of falling, as previously reported. ${ }^{14}$ The extent to which performance on the TUG and the 4- and 6-m WTs is associated with falling in the study population was also analyzed, and the regression model revealed that only performance on the TUG was significantly associated with the outcome variable (fall history) and, accordingly, to the physical performance of the older adults. This result is consistent with the idea that executive function decreases with age, ${ }^{43}$ thus affecting the physical ability to walk and to follow the TUG test instructions.

In accordance with previous studies, ${ }^{44}$ we found no association between hearing loss and falling. As in the study by Purchase-Helzner et al, ${ }^{44}$ that evaluated only women, our sample was mainly composed of females (40 out of 50), and in future studies, it would be interesting to evaluate such a relationship in men. A possible explanation for this lack of association might be that hearing loss limits the social relationships of the older adults; hence, they may be less willing to roam their environment, thus reducing their odds of suffering a fall.

Walking is one of the leading forms of mobility among older community dwellers, given that it is uncomplicated, not physically demanding, and generally accessible. ${ }^{11}$ However, it is clear that lower walking speed is associated with undesirable health outcomes. ${ }^{33}$ Consequently, any effort made to improve gait movements in the institutionalized older adults will enhance their health status and, according to our results, will reduce the incidence of falls.

All the factors found in this study related to the incidence of falls are inevitable in very old age, but they may be modified to delay or prevent negative outcomes. Therefore, public health measures should focus on day care and institutionalized populations to first detect their risk of falling through easy-to-apply assessments, such as the TUG test, and after that promote some kind of easy physical exercises to improve health, such as walking.

Nevertheless, our results must be interpreted carefully because of potential limitations. It is based on crosssectional data, which do not allow assessment of causality, and some associations were relatively weak and should be considered with caution. The sample size was too small to perform a more powerful parametric statistical analysis and to generalize the main findings. A longitudinal study with a follow-up assessment of falling incidence might confirm and quantify the effect of mobility performance on falls. In addition, perhaps due to the small sample size, demographic variables (age, gender, and educational level) were not found to be associated with fall history. Consequently, larger samples are needed to validate the use of the time taken to complete the TUG test as an indicator of fall history in the older adult population. Besides, it would be interesting for future research to determine the correlation between the 3 analyzed performance tests and their association with falls according to the type of assistance (day care center vs nursing home).

\section{CONCLUSIONS}

According to the results of this study, the correlations between the 3 testing outcomes were confirmed and 4-m and 6-m W'T performances were greater for people older than 85 years. The time taken to perform the TUG test seems to be a plausible indicator of the presence of fall history in the institutionalized older adults. No association between hearing loss and falling was found. The TUG test is considered the most suitable test to detect risk of falling compared with other common WTs (4- and 6-m WTs). The advantage of this assessment is not only the ease of performance by any participant independently of his or her age, gender, educational level, civil status, or cognitive impairment but also the lack of need of any additional devices commonly employed in more complicated performance tests. This means that the TUG assessment could be easily used as an inexpensive and reasonably brief screening tool to detect fall history in the institutionalized older adults, thus helping to reduce future costs to the health system. Nevertheless, prospective studies with larger sample sizes are needed to confirm the findings.

\section{References}

1. United Nations, Department of Economic and Social Affairs, Population Division. World population ageing: 1950-2050. http://www. un.org/esa/population/publications/worldageing 19502050/. Accessed December 5, 2014.

2. National Institute on Aging. National Institutes of Health, U.S. Department of Health \& Human Services, World Health Organization. Global health and aging. https://www.nia.nih.gov/ research/publication/global-health-and-aging/overview. Accessed December 5, 2014.

3. Stel VS, Smit JH, Plujim SMF, Lips P. Consequences of falling in older men and women and risk factors for health service use and functional decline. Age Ageing. 2014;33(1):58-65.

4. Terroso M, Rosa N, Torres Marques A, Simoes R. Physical consequences of falls in the elderly: a literature review from 1995 to 2010. Eur Rev Aging Phys Act. 2014;11(1):51-59.

5. Alkan H, Yildiz N, Sarsan A, et al. The relationship between posturographic fall risk and clinical balance tests among community-dwelling older adults. Turk Geriatri Derg. 2014;17:242-248.

6. Rubenstein LZ. Falls in older people: epidemiology, risk factors and strategies for prevention. Age Ageing. 2006;35(suppl 2):ii37-ii41.

7. Roth TN, Hanebuth D, Probst R. Prevalence of age-related hearing loss in Europe: a review. Eur Arch Otorbinolaryngol. 2011;268(8):1101-1107.

8. Lin FR, Ferrucci L. Hearing loss and falls among older adults in the United States. Arch Intern Med. 2012;172(4):369-371.

9. Foley DM, Frick KD, Lin FR. Association between hearing loss and healthcare expenditures in older adults. J Am Geriatr Soc. 2014;62(6):1188-1189.

10. Hajek A, Brettschneider C, Lange C, et al. Longitudinal predictors of institutionalization in old age. PLoS One. 2015;10(12): e0144203.

11. Simons R, Andel R. The effects of resistance training and walking on functional fitness in advanced old age. J Aging Health. 2006;18(1):91-105. 
12. Wang CY, Olson SL, Protas EJ. Physical-performance tests to evaluate mobility disability in community-dwelling elders. $J$ Aging Phys Act. 2005;13(2):184-197.

13. Newstead AH, Walden JG, Gitter AJ. Gait variables differentiating fallers from nonfallers. J Geriatr Phys Ther. 2007;30(3): 93-101

14. Yamada M, Ichihashi N. Predicting the probability of falls in community-dwelling elderly individuals using the trail-walking test. Environ Health Prev Med. 2010;15(6):386-391.

15. Podsiadlo D, Richardson S. The Timed "Up \& Go": a test of basic functional mobility for frail elderly persons. J Am Geriatr Soc. 1991;39(2):142-148.

16. Guralnik JM, Simonsick EM, Ferrucci L, et al. A short physical performance battery assessing lower extremity function: association with self-reported disability and prediction of mortality and nursing home admission. J Gerontol. 1994;49(2):M85-M94.

17. Shimada H, Tiedemann A, Lord SR, et al. Physical factors underlying the association between lower walking performance and falls in older people: a structural equation model. Arch Gerontol Geriatr. 2011;53:131-134.

18. Muñoz-Mendoza CL, Cabrero-García J, Reig-Ferrer A, CabañeroMartínez MJ. Evaluation of walking speed tests as a measurement of functional limitations in elderly people: a structured review. Int I Clin Health Psychol. 2010;10:359-378.

19. de Rekeneire N, Visser M, Peila R, et al. Is fall just a fall: correlates of falling in healthy older persons. The health, aging and body composition study. J Am Geriatr Soc. 2003;51:841-846.

20. Maki BE. Gait changes in older adults: predictors of falls or indicators of fear?. J Am Geriatr Soc. 1997;45:313-320.

21. Guralnik JM, Ferrucci L, Pieper CF, et al. Lower extremity function and subsequent disability: consistency across studies, predictive models, and value of gait speed alone compared with the Short Physical Performance Battery. I Gerontol A Biol Sci Med Sci. 2000;55A(4):M221-M231.

22. Muñoz-Mendoza CL, Cabañero-Martínez MJ, Millán-Calenti JC, Cabrero-García J, López-Sanchez R, Maseda-Rodríguez A. Reliability of 4-m and 6-m walking speed tests in elderly people with cognitive impairment. Arch Gerontol Geriatr. 2011;52 (2):e67-e70

23. Tiedemann A, Shimada H, Sherrington C, Murray S, Lord S. The comparative ability of eight functional mobility tests for predicting falls in community-dwelling older people. Age Ageing. 2008;37:430-435.

24. Peerson CU, Hansson PO, Sunnerhagen KS. Clinical tests performed in acute stroke identify the risk of falling during the first year: postural stroke study in Gothenburg (POSTGOT). J Rehabil Med. 2011;43:348-353.

25. Bandinelli S, Pozzi M, Lauretani F, et al. Adding challenge to performance-based tests of walking: the walking InCHIANTI toolkit (WIT). Am J Phys Med Rehabil. 2006;85(12):986-991.

26. Tolea MI, Costa PT, Terracciano A, et al. Sex-specific correlates of walking speed in a wide age-ranged population. J Gerontol B Psychol Sci Soc Sci. 2010;65B(2):174-184.

27. Snellen H. Test-Types for the Determination of the Acuteness of Vision. London, England: Williams and Norgate; 1862.

28. Swan IR, Browing GC. The whispered voice as a screening test for hearing impairment. J R Coll Gen Pract. 1985;35:197.
29. Blesa R, Pujol M, Aguilar M, et al. Clinical validity of the "minimental state" for Spanish speaking communities. Neuropsychologia. 2001;39(11):1150-1157.

30. Folstein MF, Folstein SE, McHugh PR. "Mini-mental state". A practical method for grading the cognitive state of patients for the clinician. J Psychiatr Res. 1975;12(3):189-198.

31. Barry E, Galvin R, Keogh C, Horgan F, Fahey T. Is the Timed Up and Go test a useful predictor of risk of falls in community dwelling older adults: a systematic review and meta-analysis. BMC Geriatr. 2014;14:14.

32. Montero-Odasso M, Schapira M, Soriano ER, et al. Gait velocity as a single predictor of adverse events in healthy seniors aged 75 years and older. J Gerontol A Biol Sci Med Sci. 2005;60(10): 1304-1309.

33. Busch TA, Duarte YA, Pires Nunes D, et al. Factors associated with lower gait speed among the elderly living in a developing country: a cross-sectional population-based study. BMC Geriatr. 2015;15:35.

34. Cesari M, Kritchevsky SB, Penninx BW, et al. Prognostic value of usual gait speed in well-functioning older people-results from the health, aging and body composition study. J Am Geriatr Soc. 2005;53(10):1675-1680.

35. Albert SM, Bear-Lehman J, Anderson SJ. Declines in mobility and changes in performance in the instrumental activities of daily living among mildly disabled community-dwelling older adults. I Gerontol A Biol Sci Med Sci. 2015;70(1):71-77.

36. van Schooten KS, Pijnappels M, Rispens SM, Elders PJM, Lips P, van Dieën JH. Ambulatory fall-risk assessment: amount and quality of daily-life gait predict falls in older adults. J Gerontol $A$ Biol Sci Med Sci. 2015;70(5):608-615.

37. Dean CM, Richards CL, Malouin F. Walking speed over 10 metres overestimates locomotor capacity after stroke. Clin Rebabil. 2001;15(4):415-421.

38. Steffen TM, Hacker TA, Mollinger L. Age- and gender-related test performance in community-dwelling elderly people: SixMinute Walk test, Berg Balance Scale, Timed Up \& Go Test, and Gait Speeds. Phys Ther. 2002;82(2):128-137.

39. Peters DM, Fritz SL, Krotish DE. Assessing the reliability and validity of a shorter walk test compared with the 10-meter walk test for measurements of gait speed in healthy, older adults. J Geriatr Phys Ther. 2013;36(1):24-30.

40. Bohannon RW. Reference values for the timed up and go test: a descriptive meta-analysis. J Geriatr Phys Ther. 2006;29(2):64-68.

41. Yim-Chiplis PK, Talbot LA. Defining and measuring balance in adults. Biol Res Nurs. 2000;1(4):321-331.

42. Lajoie Y, Gallagher SP. Predicting falls within the elderly community: comparison of postural sway, reaction time, the berg balance scale and the activities-specific balance confidence (ABC) scale for comparing fallers and non-fallers. Arch Gerontol Geriatr. 2004;38(1):11-26.

43. Royall DR, Palmer R, Chiodo LK, Polk MJ. Declining executive control in normal aging predicts change in functional status: the Freedom House Study. J Am Geriatr Soc. 2004;52(3):346-352.

44. Purchase-Helzner E, Cauley JA, Faulkner KA, et al. Hearing sensitivity and the risk of incident falls and fracture in older women: the study of osteoporotic fractures. Ann Epidemiol. 2004;14(5):311-318. 


\section{AUTHOR QUERIES}

TITLE: Timed Up and Go Test Performance as an Indicator of Fall History in Institutionalized Elderly: A Pilot Study AUTHORS: José C Millán-Calenti, Laura Núñez-Naveira, Laura Lorenzo-López, José L. Rodríguez-Villamil, Carmen L. MuñozMendoza, M. José Cabañero-Martínez, Julio Cabrero-García, and Ana Maseda

[AQ00]: Please check if authors name are correctly captured for given names (in red) and surnames (in blue) for indexing after publication.

[AQ01]: Please check whether the affiliations of all the authors are OK as typeset.

[AQ02]: Please check whether the disclosure statement is OK as typeset.

[AQ03]: Please check whether the edited sentence "The TUG results correlate ... performance." conveys the intended meaning. 